\title{
Feasibility of Permanent Stenting with Solitaire FR as a Rescue Treatment for the Reperfusion of Acute Intracranial Artery Occlusion
}

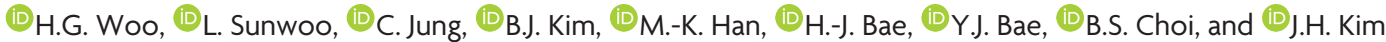

\begin{abstract}
BACKGROUND AND PURPOSE: The Solitaire FR can be used not only as a tool for mechanical thrombectomy but also as a detachable permanent stent. Our aim was to assess the feasibility and safety of permanent stent placement with the Solitaire FR compared with other self-expanding stents for intracranial artery recanalization for acute ischemic stroke.
\end{abstract}

MATERIALS AND METHODS: From January 2011 through January 2016, we retrospectively selected 2979 patients with acute ischemic stroke. Among them, 27 patients who underwent permanent stent placement (13 patients with the Solitaire FR [Solitaire group] and 14 patients with other self-expanding stents [other stent group]) were enrolled. The postprocedural modified TICI grade and angiographic and clinical outcomes were assessed. The safety and efficacy of permanent stent placement of the Solitaire FR for acute large-artery occlusion were evaluated.

RESULTS: Stent placement was successful in all cases. Modified TICI $2 \mathrm{~b}-3$ reperfusion was noted in $84.6 \%$ of the Solitaire group and in $78.6 \%$ of the other stent group. Procedural time was significantly shorter in the Solitaire group than in the other stent group $(P=.022)$. Shorter procedural time was correlated with favorable outcome $(\rho=0.46, P=.035)$. No significant differences were found in the modified $\mathrm{TICl}$ grade, NIHSS score, $\mathrm{mRS}$, and hemorrhagic transformation rate between the 2 groups. The acute in-stent thrombosis rate at discharge was significantly lower when a glycoprotein Ilb/Illa inhibitor was injected during the procedure $(P=.013)$.

CONCLUSIONS: Permanent stent placement with the Solitaire FR compared with other self-expanding stents appears to be feasible and safe as a rescue tool for refractory intra-arterial therapy.

ABBREVIATIONS: ISR $=$ in-stent restenosis; $\mathrm{mTICI}=$ modified $\mathrm{TICI}$

A cute ischemic stroke is a high-burden disease and one of the leading causes of death and neurologic disability. In 2012, the US FDA approved the Solitaire FR (Covidien, Irvine, California) after the Solitaire With the Intention For Thrombectomy (SWIFT) trial, which demonstrated that stent retriever devices had substantially high rates of recanalization. ${ }^{1}$ Five randomized trials of endovascular treatment found improvements in clinical outcomes over medical therapy and indicated that $71 \%$ of patients treated with mechanical thrombectomy had successful rep-

Received July 22, 2017; accepted after revision October 4.

From the Departments of Radiology (H.G.W., L.S., C.J., Y.J.B., B.S.C., J.H.K.) and Neurology (B.J.K., M.-K.H., H.-J.B.), Seoul National University Bundang Hospital, Bundang, Seongnam, Korea.

This work was supported by a grant from the Seoul National University Bundang Hospital Research Fund (No. 14-2016-019).

Please address correspondence to Leonard Sunwoo, MD, Department of Radiology, Seoul National University Bundang Hospital, 82 Gumi-ro 173 Beon-Gil, Seongnam, Gyeonggi-do, 13620, Republic of Korea; e-mail: leonard.sunwoo@gmail.com

三 Indicates article with supplemental on-line table.

http://dx.doi.org/10.3174/ajnr.A5477 erfusion..$^{2-7}$ These trials have proved that the stent retriever is a safe and reliable tool for endovascular reperfusion therapy. Thereafter, endovascular reperfusion therapy using the stent retriever has become the standard treatment for acute large-artery occlusion in the anterior circulation within 6 hours from onset in addition to IV tPA.

In the era of stent retriever thrombectomy, it is important to determine the appropriate strategy for acute intracranial artery occlusions refractory to conventional mechanical thrombectomy, considering the rate of unsuccessful reperfusion ranging from $14 \%$ to $41 \%$ in 5 randomized clinical trials. ${ }^{2-7}$ To that end, some case series reported outstanding procedural and clinical outcomes using self-expanding stents such as the Neuroform (Stryker Neurovascular, Kalamazoo, Michigan), Wingspan (Stryker), or Enterprise self-expanding stent (Codman \& Shurtleff, Raynham, Massachusetts) as a rescue treatment. ${ }^{8-12}$ Moreover, because acute large-artery occlusion with underlying intracranial atherosclerotic disease is more common in Asian populations than in Western populations, ${ }^{13}$ 


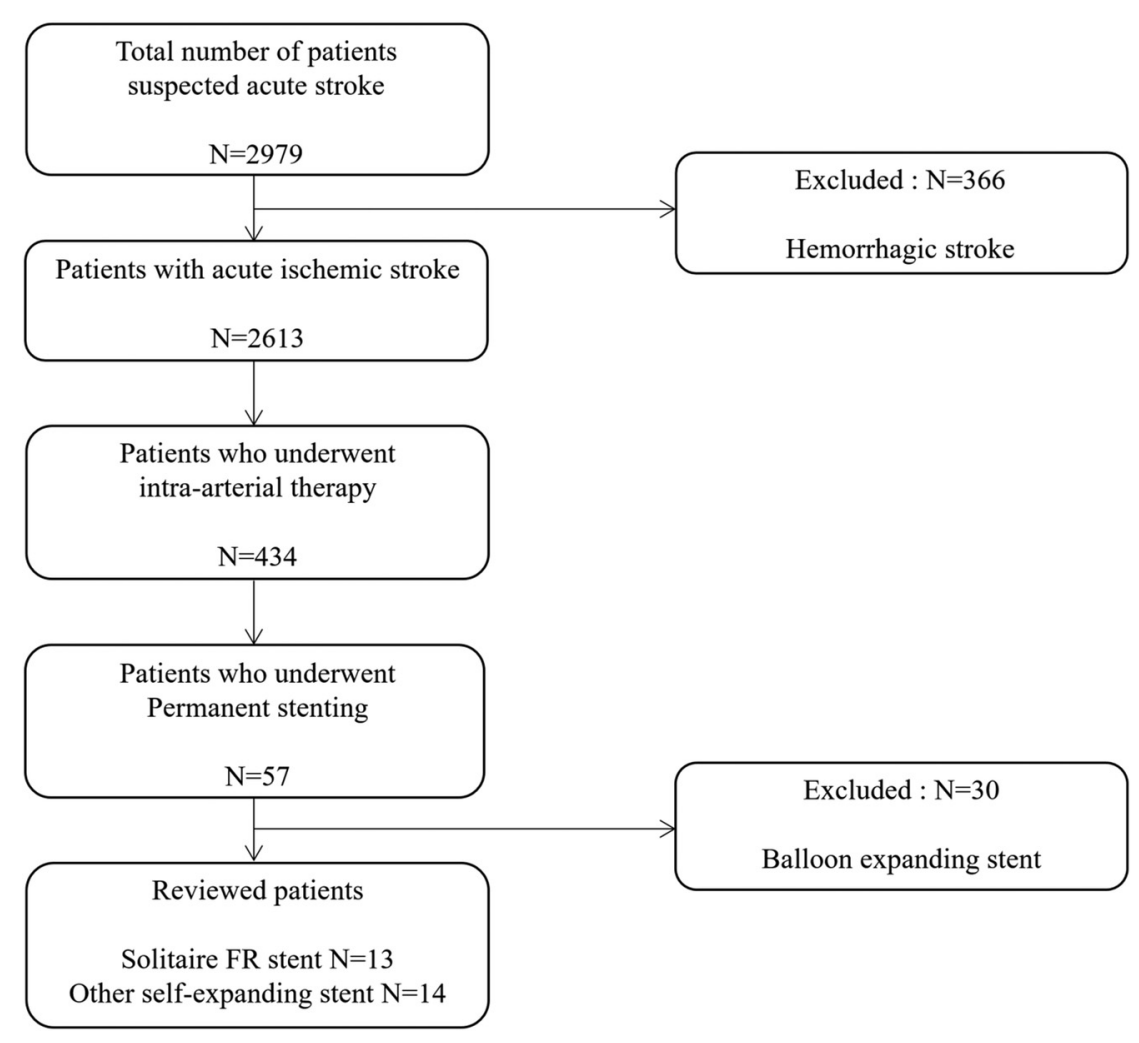

FIG 1. Flowchart of patient inclusion.

stent implantation for restoring blood flow could be particularly useful to Asian patients with atherosclerosis-related in situ stenosis or occlusion.

The Solitaire FR can be used not only as a tool for mechanical thrombectomy but also as a tool for permanent stent placement after detachment. However, to our knowledge, no study has yet been performed to assess the feasibility of permanent stent placement of the Solitaire FR to restore blood flow. At our center, Solitaire FR stent implantation is often used to treat ischemic stroke in case of unsuccessful recanalization with the Solitaire stent retriever and/or other endovascular interventions. We hypothesized that permanent stent placement with the Solitaire FR compared with other self-expanding stents may be a feasible and safe rescue treatment for intracranial artery recanalization in acute ischemic stroke.

\section{MATERIALS AND METHODS}

The institutional review board approved this retrospective study, and informed consent was waived.

\section{Subjects}

Initially, 2979 consecutive patients with acute ischemic stroke from January 2011 through January 2016 were retrospectively selected from the data base in our institution. Among them, 434 patients with suspected cerebrovascular occlusion on CTA or MRA underwent further diagnostic cerebral angiography and intra-arterial therapy. Of these, 57 patients were treated with stent insertion as a rescue treatment for recanalization of an occluded intracranial vessel. Finally, 27 patients who met the following inclusion criteria were enrolled in this study: 1) occlusion of the basilar artery, intracranial segment of vertebral artery, or MCA (M1 or M2 segment) confirmed with CTA, MRA, or DSA; and 2) permanent stent implantation as a rescue procedure. These included 13 patients who underwent permanent stent placement with the Solitaire FR (Solitaire group) and 14 patients who underwent permanent stent placement with other self-expanding stents (other stent group) (Fig 1).

\section{Procedures}

All procedures were performed on a biplane angiography machine (Integris Allura; Philips Healthcare, Best, the Netherlands). For the anterior circulation, a 9F balloon-tipped guiding catheter was guided by a $5 \mathrm{~F}$ diagnostic catheter and was placed in the distal common carotid artery or ICA. For posterior circulation, a $6 \mathrm{~F}$ shuttle and $5 \mathrm{~F}$ or $6 \mathrm{~F}$ coaxial guiding systems were placed in the extracranial vertebral artery. Initial angiography was performed to assess the occlusion level and preprocedural modified TICI (mTICI) grade. Next, mechanical thrombectomy using the Solitaire FR was performed for the occluded segment. An angiogram was obtained to thoroughly evaluate the re-establishment of flow. If the occlusion remained, the procedure was repeated immediately. For patients who had refractory occlusion or who had residual flow-compromising degree of stenosis after 3-7 attempts of mechanical thrombectomy, suction thrombectomy, or chemical thrombolysis, permanent stent placement was considered as a final bailout option. Timing of when to perform permanent stent placement and deciding what kind of stent would be used were at the discretion of the neurointerventionalist. A glycoprotein IIb/ IIIa inhibitor (tirofiban) was administered intravenously if the patient was about to undergo permanent stent insertion and had not taken proper antithrombotic medication before the procedure. ${ }^{14}$ The glycoprotein IIb/IIIa inhibitor was initially injected as a loading dose $(0.4 \mathrm{mcg} / \mathrm{kg})$ for 30 minutes, followed by continuous infusion for prevention of acute in-stent thrombosis $(0.1$ $\mathrm{mcg} / \mathrm{kg} / \mathrm{min})$. The patients immediately received additional oral acetylsalicylic acid $(300 \mathrm{mg})$ and clopidogrel $(75 \mathrm{mg})$ to protect the stent after excluding symptomatic hemorrhagic transformation and/or brain edema with significant mass effect with brain CT on the following day.

\section{Evaluation of Outcomes and Clinical and Angiographic Follow-Up}

The mTICI reperfusion grade and change of neurologic deficit were assessed at the end of the procedure. Successful recanalization was defined as mTICI $2 \mathrm{~b}-3$ recanalization on a delayed angiogram obtained after at least 10 minutes. The procedural success of permanent stent placement was defined as accurate 

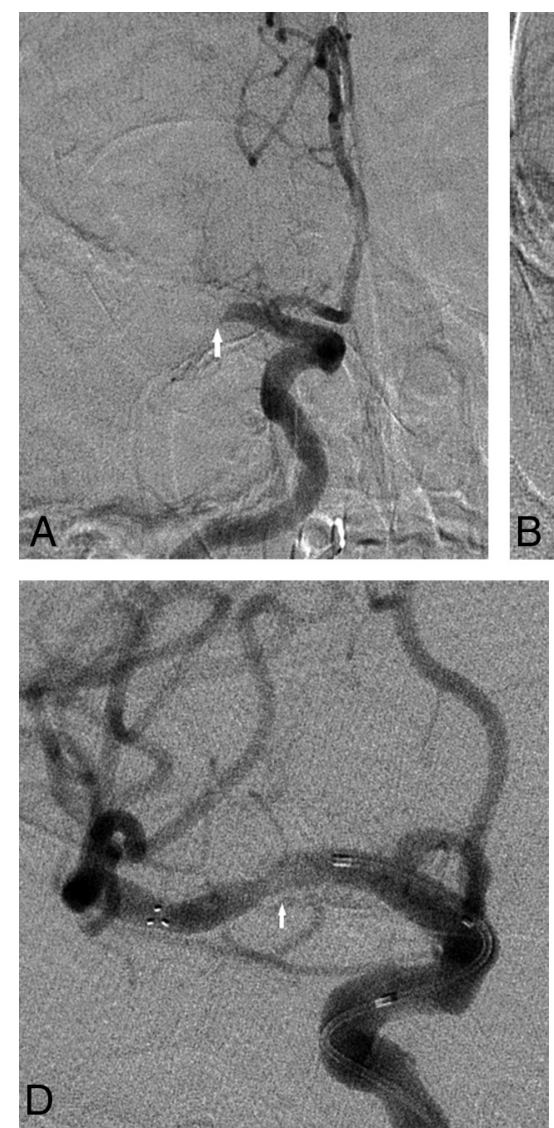
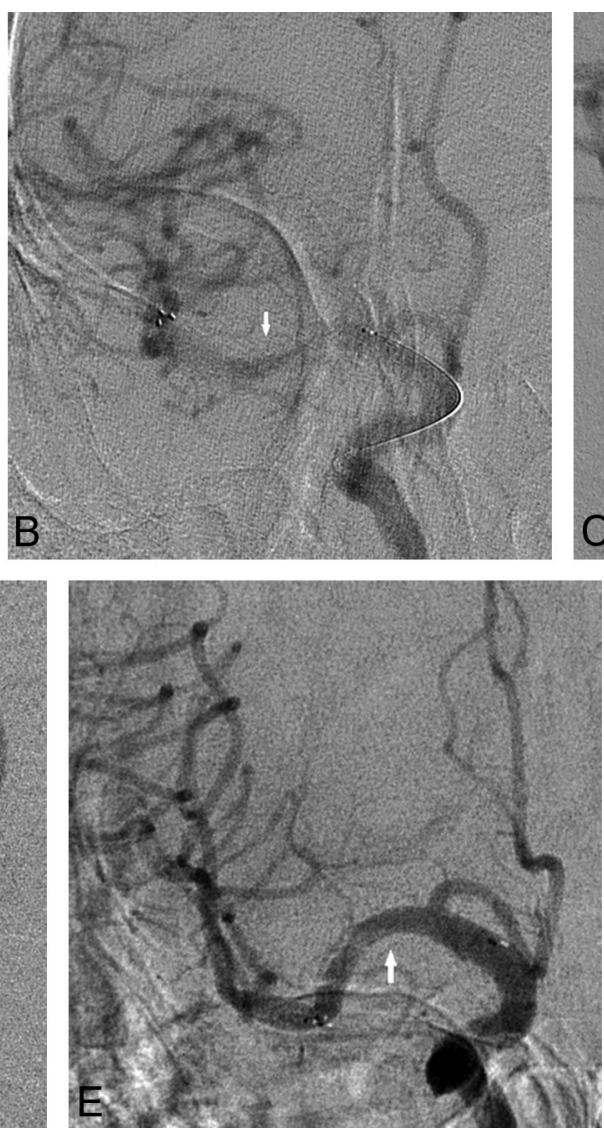
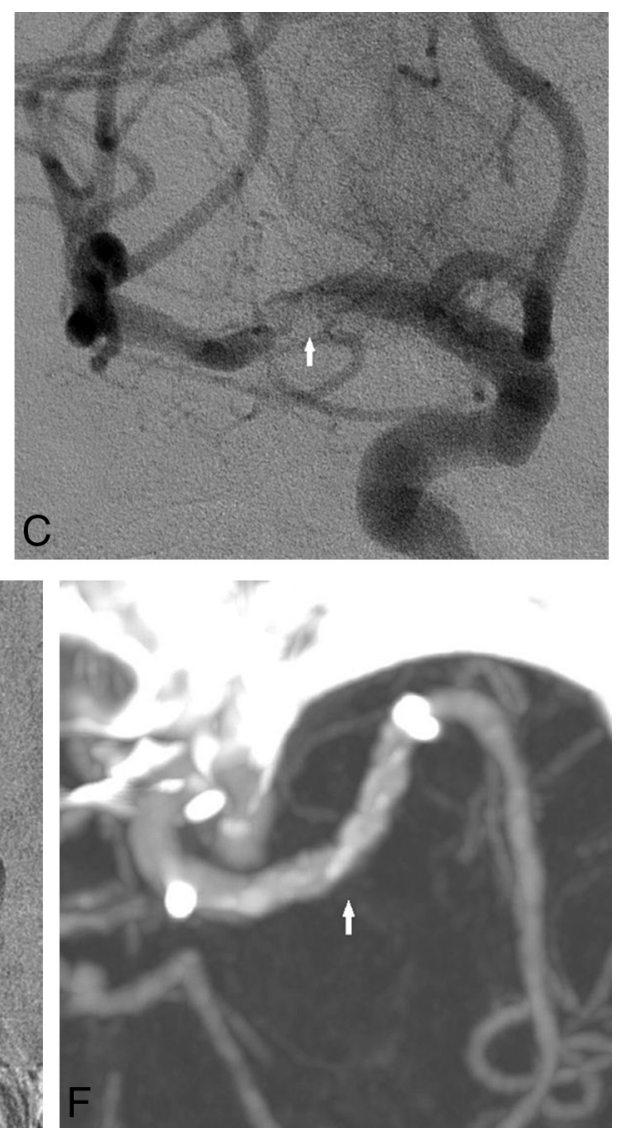

FIG 2. A 55-year-old man with acute ischemic stroke, presenting with an initial NIHSS score of 22. A, A right internal carotid angiogram shows occlusion of the right middle cerebral artery M1 portion. B, Initial placement of the Solitaire stent. A right internal carotid angiogram shows visible anterograde flow in the right middle cerebral artery M1 portion. C, A 5-minute delayed right internal carotid angiogram after thrombectomy using the Solitaire stent shows repeat buildup of thrombus and reocclusion. $D$, After 3 passages of the Solitaire stent with recurrent reocclusion, the decision for a permanent stent was made. A right internal carotid angiogram during the intravenous infusion of glycoprotein Ilb/IIla inhibitor shows a patent lumen of a temporarily deployed Solitaire stent. E, A 30-minute delayed angiogram after detachment of the Solitaire stent reveals complete recanalization. $F$, A follow-up angiogram at 3 months reveals a patent right middle cerebral artery with no evidence of in-stent restenosis at the Ml portion. The patient had an mRS score of 1 at 3 months.

delivery and deployment of the stent completely covering the target lesion and resulting in a residual stenosis of $<50 \%$. Angiographic follow-up was scheduled at discharge and 3 months after discharge, with DSA or CTA to assess in-stent restenosis (ISR). ISR was defined as absolute stenosis of $>50 \%$ within the stent, including its margin, or $\geq 20 \%$ reduction of the lumen size relative to the residual stenosis.

Clinical outcomes were evaluated according to the NIHSS score at admission, after intra-arterial therapy, and at discharge and according to the mRS at discharge and 3, 6, and 12 months. The initial and follow-up clinical evaluations were performed by 3 experienced stroke neurologists. Good functional outcome was defined as an $\mathrm{mRS}$ of $0-2$, whereas poor outcome was defined as an mRS of 3-6. We defined symptomatic brain hemorrhage as parenchymal, subarachnoid, or intraventricular hemorrhage detected by CT or MR imaging that was associated with new neurologic signs or symptoms lasting $\geq 24$ hours or a seizure. ${ }^{15,16}$ In addition, we evaluated mortality at 3, 6, and 12 months (Fig 2).

\section{Statistical Methods}

Statistical analysis was performed using SPSS 22.0 for Windows (IBM, Armonk, New York). Clinical and laboratory findings and outcomes between the Solitaire group and the other stent group were compared. The Mann-Whitney $U$ test, $\chi^{2}$ test, or Fisher exact test was used to analyze categoric variables. A Spearman correlation coefficient was used to assess the correlation between the variables. Frequency, median, and interquartile ranges were used for descriptive statistics.

\section{RESULTS}

The On-line Table summarizes the clinical characteristics, treatment, and outcome in the Solitaire group and the other stent group. No significant differences were found in demographic information, lesion location, comorbidities, Trial of Org 10172 in Acute Stroke Treatment (TOAST) classification, ${ }^{17}$ NIHSS score at admission, and outcome between the 2 groups.

Stent placement was successful in all procedures, and mTICI 2b-3 recanalization was obtained in 11 patients $(84.6 \%)$ in the Solitaire group and 11 patients $(78.6 \%)$ in the other stent group $(P>.9)$. Total procedural time was significantly shorter in the Solitaire group compared with the other stent group (69 versus 115 minutes, $P=.022$ ). There were no significant differences in onset-to-emergency department time, onset-to-angiography 


\begin{tabular}{|c|c|c|c|}
\hline & \multicolumn{2}{|c|}{ GP IIb/IIla Inhibitors } & \multirow{2}{*}{$\begin{array}{c}P \\
\text { Value }\end{array}$} \\
\hline & Yes & No & \\
\hline ISR at discharge (yes) (\%) & $0 / 16(0)$ & $3 / 3(50.0)$ & $.013^{\mathrm{a}}$ \\
\hline ISR at 3 mo (yes) (\%) & $2 / 9(18.2)$ & $4 / 1(80.0)$ & $.036^{\mathrm{a}}$ \\
\hline $\begin{array}{l}\text { Postprocedural mTICl } \\
\text { grade }(0-2 a / 2 b-3)(\%)\end{array}$ & 2/16 (11.1/88.9) & $3 / 6(33.3 / 66.7)$ & .295 \\
\hline $\begin{array}{l}\text { Overall hemorrhagic } \\
\text { transformation (yes) (\%) }\end{array}$ & $3 / 15$ (16.7) & $4 / 5(44.4)$ & .175 \\
\hline Symptomatic ICH (yes) (\%) & $1 / 17(5.6)$ & $2 / 7(22.2)$ & .250 \\
\hline $\mathrm{mRS}$ at $3 \mathrm{mo} 0-2(\%)$ & $8 / 18(44.4)$ & $0 / 9(0)$ & $.026^{\mathrm{a}}$ \\
\hline $\mathrm{mRS}$ at $6 \mathrm{mo} 0-2(\%)$ & $9 / 18(50.0)$ & $2 / 9(22.2)$ & .231 \\
\hline mRS at 12 mo 0-2 (\%) & $9 / 18(50.0)$ & $2 / 9(22.2)$ & .231 \\
\hline Mortality at 3 mo (\%) & $3 / 15(16.7)$ & $4 / 5(44.4)$ & .175 \\
\hline Mortality at 6 mo (\%) & $4 / 14(22.2)$ & $4 / 5(44.4)$ & .375 \\
\hline Mortality at $12 \mathrm{mo}(\%)$ & $4 / 14(22.2)$ & $4 / 5(44.4)$ & .375 \\
\hline
\end{tabular}

Note:-GP indicates glycoprotein.

a Significant.

time, and onset-to-reperfusion time between the 2 groups. The postprocedural NIHSS score and mRS at discharge and at 3, 6, and 12 months were also not statistically different between the 2 groups (On-line Table).

Procedural time showed a moderate positive correlation with mRS at 3 months and mRS at 6 months, respectively ( $\rho=0.47$, $P=.030$ and $\rho=0.46, P=.035$, respectively). However, no significant correlation was found between the time from onset to reperfusion and clinical outcome.

During the procedure, a glycoprotein IIb/IIIa inhibitor was administered in 7 of 13 patients $(53.8 \%)$ in the Solitaire group and 11 of 14 patients $(78.6 \%)$ in the other stent group $(P=.236)$ (On-line Table). There was a trend toward a higher rate of mTICI $2 \mathrm{~b}-3$ recanalization when the glycoprotein IIb/IIIa inhibitor was used than when it was not used ( $88.9 \%$ versus $66.7 \%)$, but statistical significance was not reached $(P=.295)$ (Table).

There were no significant differences in ISR at discharge and at 3 months between the 2 groups (On-line Table). However, both ISR at discharge and ISR at 3 months were significantly lower when a glycoprotein IIb/IIIa inhibitor was administered during the procedure $(P=.013$ and $P=.036$, respectively). Also, the proportion of favorable mRS (0-2) at 3 months was significantly higher in the patients who were administered a glycoprotein IIb/ IIIa inhibitor during the procedure compared with those who were not $(P=.026)$ (Table). No significant difference was noted in ISR at discharge between patients with cancer and those without cancer.

Rates of overall hemorrhagic transformation and symptomatic intracerebral hemorrhage in the Solitaire group (15.4\% and $0 \%$, respectively) were not significantly different from those in the other stent group (35.7\% and $21.4 \%$, respectively) (On-line Table). Also, mortalities at 3, 6, and 12 months in the Solitaire group $(23.1 \%, 30.8 \%$, and $30.8 \%$, respectively) were not significantly different from those in the other stent group $(28.6 \%, 28.6 \%$, and $28.6 \%$, respectively) (On-line Table).

Three patients in the Solitaire group died of respiratory failure with underlying metastatic cancer (bronchial bleeding due to disseminated intravascular coagulation, sepsis and pneumonia, and malignant pleural effusion and pneumonia) at 3 months, and 1 patient in the Solitaire group died of respiratory failure with underlying cancer (sepsis and pancytopenia) at 6 months. Three patients in the other stent group died of cerebral herniation caused by malignant cerebral edema or intracerebral hemorrhage at discharge, and 1 patient in the other stent group died of pneumonia and sepsis at 3 months.

\section{DISCUSSION}

We have shown that permanent detachment of the Solitaire FR achieved mTICI $2 \mathrm{~b}-3$ recanalization in $84.6 \%$ of patient with acute ischemic stroke in whom mechanical thrombectomy had failed. Total procedural time was significantly shorter in the Solitaire group than in the other stent group $(P=.022)$. Shorter procedural time was correlated with favorable outcome ( $\rho=0.46$, $P=.035)$. There were no significant differences in discharge NIHSS score; mRS at 3, 6, and 12 months; complication rates such as symptomatic intracerebral hemorrhage; and mortality between the 2 groups. This finding suggests that permanent stent placement with the Solitaire FR might be considered a rescue therapy in preference to other self-expanding stents for failed mechanical thrombectomy in patients with acute intracranial artery occlusion. The efficacy and safety of permanent stent placement using other self-expanding stents for recanalization of acute intracranial vessel occlusion have been evaluated in several previous studies. ${ }^{8-12}$ However, to our knowledge, there has been no study that compares the outcome of the Solitaire FR stent with that of other self-expanding stents for rescue treatment.

For the prevention of recurrent stroke, intracranial artery stent placement is not recommended as the first-line treatment of intracranial atherosclerosis according to the Stenting vs Aggressive Medical Management for Preventing Recurrent Stroke in Intracranial Stenosis (SAMMPRIS) ${ }^{18}$ trial, which reported early morbidity as high as $14.7 \%$ in the stent placement group. However, in the acute setting, several case series demonstrated high recanalization rates of $74.5 \%-92 \%$ for intracranial stent placement when other endovascular methods had failed..$^{8-10,19,20}$ Self-expanding stents (eg, Neuroform, Wingspan, or Enterprise) have been used in most patients in these series.

Intracranial atherosclerotic disease is more common in Asian populations than in Western populations, ${ }^{13}$ though the reason remains unclear. Possible explanations include the inherited susceptibility of intracranial vessels to atherosclerosis, acquired differences in the prevalence of risk factors, and differential responses to the same risk factors. ${ }^{13}$ Thrombus lodged in segments of underlying intracranial atherosclerotic stenosis may become refractory to mechanical disruption or clot retrieval. Therefore, intracranial artery stent placement might be considered a feasible option in the treatment of Asian patients with acute large-artery occlusion. Recently, Baek et $\mathrm{al}^{20}$ demonstrated more favorable outcomes in the stent group than in the nonstent group in Korean populations. In addition, studies from East Asia have shown lower rates of periprocedural complications and morbidities in patients with intracranial stent placement when other endovascular procedures failed to achieve recanalization. ${ }^{13,21-26}$

In addition to a tool for mechanical thrombectomy, the Solitaire FR can also be used as a permanent stent because it is detachable. ${ }^{27}$ In this study, we achieved an mTICI of $2 \mathrm{~b}-3$ in $84.6 \%$ of the cases in Solitaire group, comparable with $78.6 \%$ in the other 
stent group. Moreover, because permanent stent placement using the Solitaire FR does not require the insertion of another device, the use of the Solitaire FR can significantly reduce the procedural time as well as cost. Consequently, this might reduce the time interval from stroke onset to reperfusion and hence might potentially reduce the risk of periprocedural complications. In this study, shorter procedural time was correlated with favorable outcome. In addition, although no statistical significance was found, there were trends toward lower rates of symptomatic intracerebral hemorrhage and overall hemorrhagic transformation in the Solitaire group compared with the other stent group. Another advantage of the Solitaire FR in relation to other self-expandable stents is that the Solitaire FR enables the assessment of vessel patency during its temporary placement. When antegrade flow is restored and the target vessel lumen is patent during the temporary deployment of the Solitaire stent but recurrent occlusion after stent retrieval occurs, permanent detachment of the Solitaire FR can be an option.

The combination of thrombolytics and the glycoprotein IIb/ IIIa antagonist has been shown to have a synergistic effect on the recanalization efficiency in other studies. ${ }^{14,28}$ In this study, the use of glycoprotein IIb/IIIa antagonists was based on the likely mechanism of stroke. When underlying intracranial atherosclerotic stenosis was suspected and when recurrent buildup of thrombus was noted during the temporary placement of the stent, then the glycoprotein IIb/IIIa inhibitor was particularly considered. Although the immediate postprocedural success rate (mTICI grade 2b-3) regarding glycoprotein IIb/IIIa inhibitor usage was not significantly different ( $88.9 \%$ versus $66.7 \%, P=.295$ ), we observed better angiographic outcomes at discharge and at 3 months and better clinical outcomes at 3 months when a glycoprotein IIb/IIIa antagonist was used during the procedure $(P=.013, P=.036$, and $P=.026$, respectively). Because a glycoprotein IIb/IIIa antagonist prevents acute thrombus formation and subsequent distal embolization by inhibiting the final common pathway of platelet aggregation, its effect may be seen more often during the early phase after the onset of stroke. No significant difference was found in overall complication rates based on the use of a glycoprotein IIb/IIIa antagonist.

As with any other intracranial stents, dual antithrombotic therapy is recommended to prevent delayed thrombosis within the stent. ${ }^{19,29}$ Patients in our study were routinely given aspirin in combination with clopidogrel. However, initiating these drugs may be difficult in an acute setting when IV tPA has been administered. In this situation, delayed initiation of antiplatelet medication by at least 24 hours is recommended to reduce the risk of symptomatic intracranial hemorrhage. ${ }^{30}$

In addition to the retrospective nature of this study, our study has a few limitations. First, although most clinical characteristics and outcome variables were comparable between the Solitaire group and the other stent group, a noninferiority test could not be performed due to the small sample size. A follow-up study with a larger study population and a longer follow-up period would be desirable. Second, the inclusion of patients with underlying cancer might have led to difficulties in interpreting clinical outcomes.

\section{CONCLUSIONS}

Compared with other self-expandable stents, the permanent deployment of the Solitaire FR as a rescue therapy for reperfusion of intracranial artery occlusion appears to be feasible and safe and requires a shorter procedural time.

Disclosures: Leonard Sunwoo—RELATED: Grant: Seoul National University Bundang Hospital Research Fund (No. 14-2016-019).

\section{REFERENCES}

1. Saver JL, Jahan R, Levy EI, et al; SWIFT Trialists. Solitaire flow restoration device versus the Merci Retriever in patients with acute ischaemic stroke (SWIFT): a randomised, parallel-group, non-inferiority trial. Lancet 2012;380:1241-49 CrossRef Medline

2. Berkhemer OA, Fransen PS, Beumer D, et al. A randomized trial of intraarterial treatment for acute ischemic stroke. NEngl JMed 2015; 372:11-20 CrossRef Medline

3. Campbell BC, Mitchell PJ, Kleinig TJ, et al; EXTEND-IA Investigators. Endovascular therapy for ischemic stroke with perfusion-imaging selection. N Engl J Med 2015;372:1009-18 CrossRef Medline

4. Goyal M, Demchuk AM, Menon BK, et al; ESCAPE Trial Investigators. Randomized assessment of rapid endovascular treatment of ischemic stroke. N Engl J Med 2015;372:1019-30 CrossRef Medline

5. Jovin TG, Chamorro A, Cobo E, et al; REVASCAT Trial Investigators. Thrombectomy within $\mathbf{8}$ hours after symptom onset in ischemic stroke. N Engl J Med 2015;372:2296-306 CrossRef Medline

6. Saver JL, Goyal M, Bonafe A, et al; SWIFT PRIME Investigators. Stent-retriever thrombectomy after intravenous t-PA vs. t-PA alone in stroke. N Engl J Med 2015;372:2285-95 CrossRef Medline

7. Goyal M, Menon BK, van Zwam WH, et al; HERMES collaborators. Endovascular thrombectomy after large-vessel ischaemic stroke: a meta-analysis of individual patient data from five randomised trials. Lancet 2016;387:1723-31 CrossRef Medline

8. Brekenfeld C, Schroth G, Mattle HP, et al. Stent placement in acute cerebral artery occlusion: use of a self-expandable intracranial stent for acute stroke treatment. Stroke 2009;40:847-52 CrossRef Medline

9. Levy EI, Mehta R, Gupta R, et al. Self-expanding stents for recanalization of acute cerebrovascular occlusions. AJNR Am J Neuroradiol 2007;28:816-22 Medline

10. Zaidat OO, Wolfe T, Hussain SI, et al. Interventional acute ischemic stroke therapy with intracranial self-expanding stent. Stroke 2008; 39:2392-95 CrossRef Medline

11. Levy EI, Siddiqui AH, Crumlish A, et al. First Food and Drug Administration-approved prospective trial of primary intracranial stenting for acute stroke: SARIS (stent-assisted recanalization in acute ischemic stroke). Stroke 2009;40:3552-56 CrossRef Medline

12. Levy EI, Rahman M, Khalessi AA, et al. Midterm clinical and angiographic follow-up for the first Food and Drug Administration-approved prospective, single-arm trial of primary stenting for stroke: SARIS (Stent-Assisted Recanalization for Acute Ischemic Stroke). Neurosurgery 2011;69:915-20; discussion 920 CrossRef Medline

13. Kim JS, Bonovich D. Research on intracranial atherosclerosis from the East and West: why are the results different? J Stroke 2014;16: 105-13 CrossRef Medline

14. Abou-Chebl A, Bajzer CT, Krieger DW, et al. Multimodal therapy for the treatment of severe ischemic stroke combining GPIIb/IIIa antagonists and angioplasty after failure of thrombolysis. Stroke 2005; 36:2286-88 CrossRef Medline

15. Hacke W, Kaste M, Fieschi C, et al. Randomised double-blind placebo-controlled trial of thrombolytic therapy with intravenous alteplase in acute ischaemic stroke (ECASS II): Second EuropeanAustralasian Acute Stroke Study Investigators. Lancet 1998;352: 1245-51 CrossRef Medline

16. Hacke W, Kaste M, Bluhmki E, et al; ECASS Investigators. Thrombolysis with alteplase 3 to 4.5 hours after acute ischemic stroke. N Engl J Med 2008;359:1317-29 CrossRef Medline

AJNR Am J Neuroradiol 39:331-36 Feb 2018 www.ajnr.org 
17. Adams HP Jr, Bendixen BH, Kappelle LJ, et al; TOAST Investigators. Classification of subtype of acute ischemic stroke: definitions for use in a multicenter clinical trial. Stroke 1993;24:35-41 Medline

18. Chimowitz MI, Lynn MJ, Derdeyn CP, et al; SAMMPRIS Trial Investigators. Stenting versus aggressive medical therapy for intracranial arterial stenosis. N Engl J Med 2011;365:993-1003 CrossRef Medline

19. Levy EI, Ecker RD, Horowitz MB, et al. Stent-assisted intracranial recanalization for acute stroke: early results. Neurosurgery 2006;58: 458-63; discussion 458-63 CrossRef Medline

20. Baek JH, Kim BM, Kim DJ, et al. Stenting as a rescue treatment after failure of mechanical thrombectomy for anterior circulation large artery occlusion. Stroke 2016;47:2360-63 CrossRef Medline

21. Ramee SR, Subramanian R, Felberg RA, et al. Catheter-based treatment for patients with acute ischemic stroke ineligible for intravenous thrombolysis. Stroke 2004;35:e109-111 CrossRef Medline

22. Gupta R, Vora NA, Horowitz MB, et al. Multimodal reperfusion therapy for acute ischemic stroke: factors predicting vessel recanalization. Stroke 2006;37:986-90 CrossRef Medline

23. Sauvageau E, Samuelson RM, Levy EI, et al. Middle cerebral artery stenting for acute ischemic stroke after unsuccessful Merci retrieval. Neurosurgery 2007;60:701-06; discussion 706 CrossRef Medline

24. Sauvageau E, Levy EI. Self-expanding stent-assisted middle cerebral artery recanalization: technical note. Neuroradiology 2006;48:405-08 CrossRef Medline
25. Fitzsimmons BF, Becske T, Nelson PK. Rapid stent-supported revascularization in acute ischemic stroke. AJNR Am J Neuroradiol 2006; 27:1132-34 Medline

26. Jeon P, Kim BM, Kim DI, et al. Emergent self-expanding stent placement for acute intracranial or extracranial internal carotid artery dissection with significant hemodynamic insufficiency. AJNR Am J Neuroradiol 2010;31:1529-32 CrossRef Medline

27. Stampfl S, Hartmann M, Ringleb PA, et al. Stent placement for flow restoration in acute ischemic stroke: a single-center experience with the Solitaire stent system. AJNR Am J Neuroradiol 2011;32: 1245-48 CrossRef Medline

28. Seo JH, Jeong HW, Kim ST, et al. Adjuvant tirofiban injection through deployed Solitaire stent as a rescue technique after failed mechanical thrombectomy in acute stroke. Neurointervention 2015; 10:22-27 CrossRef Medline

29. Bose A, Hartmann M, Henkes H, et al. A novel, self-expanding, nitinol stent in medically refractory intracranial atherosclerotic stenoses: the Wingspan study. Stroke 2007;38:1531-37 CrossRef Medline

30. Adams HP Jr, Adams RJ, Brott T, et al; Stroke Council of the American Stroke Association. Guidelines for the early management of patients with ischemic stroke: a scientific statement from the Stroke Council of the American Stroke Association. Stroke 2003;34:1056-83 CrossRef Medline 